\title{
Regional prevalence of HIV among antenatal patients
}

\author{
Pranoy Nath \\ Correspondence: Dr Pranoy Nath, Associate Professor, Department of Obstetrics and \\ Gynaecology, Silchar Medical College, Silchar, Assam, India; Email - drnathdas@gmail.com \\ Distributed under Creative Commons Attribution-Share Alike 4.0 International.
}

\begin{abstract}
Objective: This study was done to determine the changing trends in the prevalence of HIV in antenatal patients. Methodology: The data was collected for a period of 10 years from January 2007 to December 2016. All pregnant patients attending ANC clinic and getting admitted in labour room were counselled for HIV testing. Data is analysed and prevalence trend of HIV in antenatal patients is determined. Results: The number of patients counselled for HIV testing has increased from $46.42 \%$ in 2007 to $100 \%$ for the past 2 years. The trend of HIV prevalence appears to be continuously declining among ANC clinic attendees from 2007 to 2016. Conclusion: This study reflects the national trends. Prevalence shows decline in recent years although fluctuations are seen.
\end{abstract}

Keywords: Prevalence, HIV, counselling.

From the diagnosis of first HIV case in Chennai in 1986, India has experienced a sharp rise in the number of cases detected with HIV. Recently the trend is on a slow decline owing to the various programmes and policies implemented by the government of India for educating the people, diagnosis and treatment, thereby decreasing the spread and in turn incidence of the disease.

In India, the predominant mode of HIV transmission is through heterosexual contact. Therefore most women get infected in their reproductive age group. In the absence of treatment, the risk of vertical transmission of HIV in babies born to these mothers is as high as 25$30 \%$.

The trend of new or incident infections, especially in young people who have recently become sexually active, is the most sensitive marker to track the course of the HIV epidemic. Unfortunately, incidence is hard to measure directly, but prevalence in young women is an indirect but useful proxy ${ }^{1}$. Burden of HIV in pregnant women and children follows overall HIV epidemic in India. Accordingly, HIV data from antenatal women has been used to monitor trends in the general population and to predict the sero-prevalence in young children ${ }^{2,3}$.

This retrospective study is done to determine the changing trends in the prevalence of HIV in antenatal patients attending PPTCT clinic in Silchar medical college and hospital, Assam.

\section{Methods}

This retrospective study was done by collecting data from the PPTCT centre, for a period of 10 years from

Received: $13^{\text {th }}$ February 2017. Accepted: $17^{\text {th }}$ April 2017.

Nath P. Regional prevalence of HIV among antenatal patients. The New Indian Journal of OBGYN. 2017; 4(1):47-9 
January 2007 to December 2016 and analysing and comparing the data with national figures. According to PPTCT program, all pregnant patients attending ANC clinic and getting admitted in labour room are counseled for HIV testing. Opt-out strategy is followed. Informed and written consent are taken and provided with a patient identity. Venous blood of $5 \mathrm{ml}$ is taken from the patient in a sterile container. The samples are tested according to strategy III of National AIDS Control Organisation (NACO) guidelines. Three serial antibody tests are performed. Data is analysed and year wise positive results and prevalence trend of HIV in antenatal patients is determined.

\section{Results}

A total of 51,904 ANC patients attending at Silchar Medical College PPTCT centre on attending doctor's advice, over a period of ten years, were counseled for HIV testing and 49,205 of them opted for HIV testing. One hundred thirty five (135) were positive for HIV, giving an overall positivity of $0.274 \%$ (table 1).

The number of patients counseled for HIV testing who opted for testing has increased from $46.42 \%$ in 2007 to $100 \%$ for the past $2-4$ years, reflecting the success of educational and motivational tools of the government.

\section{Discussion}

A comprehensive and consistent approach is necessary to determine and monitor the HIV levels and trends, as they help in public health management and policy making. As per recently released, India HIV estimation report, National adult (15-49yrs) HIV prevalence in India is estimated at $0.26 \%$ in 2015 including $0.30 \%$ among males and $0.22 \%$ among females. Among the states, Manipur has shown the highest estimated adult HIV prevalence of $1.15 \%$. All other states except high prevalence states have adult HIV prevalence of less than $0.20 \%{ }^{4}$.
At national level, the prevalence has continued its steady decline from estimated peak of $0.38 \%$ in 2001 03 through $0.34 \%$ in 2007 and $0.28 \%$ in 2012 and $0.26 \%$ in $2015^{4}$.
Table 1: HIV positivity over a period of ten years

\begin{tabular}{|llllll}
\hline Years & $\begin{array}{l}\text { No. of ANC } \\
\text { counseled }\end{array}$ & $\begin{array}{l}\text { No. } \\
\text { ANC tested }\end{array}$ & $\begin{array}{l}\text { No. } \\
\text { positive cases }\end{array}$ & $\begin{array}{l}\text { Percentage } \\
(\%)\end{array}$ \\
\hline 2007 & 2085 & 968 & 5 & 0.516 \\
\hline 2008 & 3434 & 3377 & 6 & 0.177 \\
\hline 2009 & 3414 & 3414 & 11 & 0.322 \\
\hline 2010 & 4919 & 4918 & 6 & 0.122 \\
\hline 2011 & 6740 & 6740 & 17 & 0.252 \\
\hline 2012 & 6364 & 6272 & 17 & 0.271 \\
\hline 2013 & 5800 & 5800 & 19 & 0.327 \\
\hline 2014 & 5897 & 5867 & 13 & 0.221 \\
\hline 2015 & 5812 & 5812 & 25 & 0.43 \\
\hline 2016 & 5957 & 5957 & 15 & 0.252 \\
\hline Total & $\mathbf{5 1 , 9 0 4}$ & $\mathbf{4 9 , 2 0 5}$ & $\mathbf{1 3 5}$ & $\mathbf{0 . 2 7 4}$ \\
\hline
\end{tabular}

The trend appears to be continuously declining among ANC clinic attendees. The HIV prevalence observed among ANC clinic attendees during 2014-15 was $0.29 \%$. State-wise data shows that Assam is one of

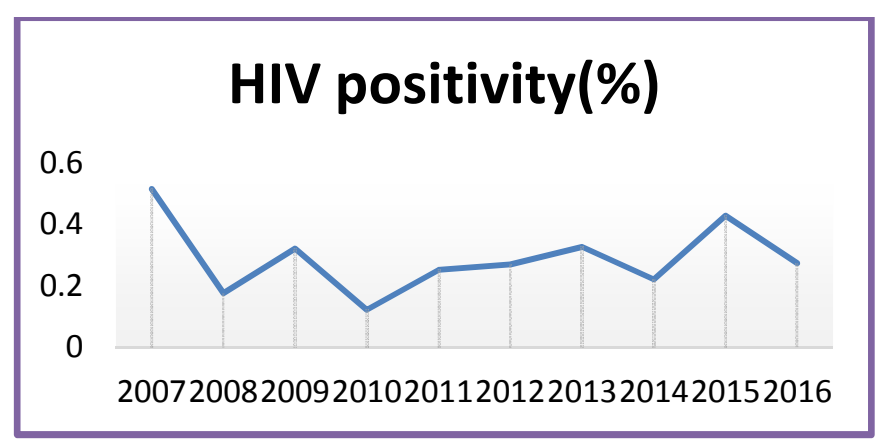

Fig 1: HIV positive case 2007-2017

the low prevalence areas with $0.18 \%$ of HIV prevalence ${ }^{4}$. The low prevalence states of Assam, Bihar,Chattisgarh, Jharkhand and Uttarkhand showed rising trends of HIV prevalence among ANC clinic attendees at levels of less that $0.50 \%$. 


\section{Conclusion}

According to this study, the prevalence of HIV in pregnant patients from the local area is more than the state and national average. This result is disturbing in that if the prevalence in unsuspecting young women is high, then the actual prevalence of HIV in the community may be higher than the estimated numbers. And as high prevalence in ANC patients reflects the HIV prevalence in children, more studies and interventions might be necessary to determine and treat the actual cases in the region of Silchar and surrounding areas.

Conflict of interest: None. Disclaimer: Nil.

\section{References}

1.Kumar R, Jha P, Arora P, Mony P, Bhatia P, Millson P, Dhingra N, Bhattacharya M, Remis RS, Nagelkerke N. Trends in HIV-1 in young adults in south India from
2000-2004: a prevalence study. Lancet. 2006; 367: 116472.

2.Zaba B, Boerma T, White R. Monitoring the AIDS epidemic using HIV prevalence data among young women attending antenatal clinics: prospects and problems. AIDS. 2000; 14: 1633-45.

3.Boerma JT, Ghys PD, Walker N. Estimates of HIV-1 prevalence from national population-based surveys as a new gold standard. Lancet. 2003; 362:1929-31.

4.NACO. India HIV estimations 2015-annual report. New Delhi: National Institute of Medical Statistics; 2015.

5.NACO. ANC HIV Sentinel surveillance national report 2014-15. New Delhi: NACO; 2015.

\section{Pranoy Nath ${ }^{1}$}

${ }^{1}$ Associate Professor, Department of Obstetrics and Gynaecology, Silchar Medical College, Silchar, Assam, India 